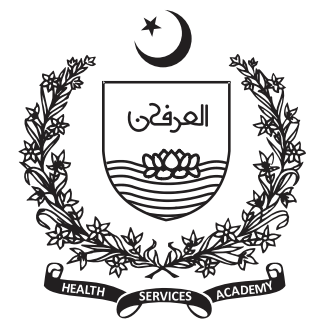

1,6Senior Medical Officer. Health Department, Govt of Sindh

2,3Associate Professor, Department of Community Medicine Fazaia Medical College Islamabad-

Pakistan,

4Deputy Town Health Officer (Preventive) Site

Town Karachi,

5Gynea and Obstetrics: DUMHS Karachi-Pakistan.

7Staff at Health

Department, Govt of Sindh

Corresponding Author:

Mazhar ul Haq Nizamani Email:

msphs15mazharulhaq@hsa. edu.pk

\section{Knowledge and Practices Regarding Infant and Young Child Feeding among Mothers' Children 0-23 Months of Matli, District Badin, Sindh}

\author{
Mazhar ul Haq Nizamani ${ }^{1}$, Rukhsana Khan², Arshia Bilal ${ }^{3}$, Lajpat ${ }^{4}$ \\ Saira Almas ${ }^{5}$,Muhammad Ali Balouch ${ }^{6}$, Shahida Khan ${ }^{7}$
}

\section{Abstract}

Background: Lack of proper practices account for the deaths of 1.4 million children of $<5$ years globally. Optimal Infant and Young Child Feeding practices are recognized as the most valuable approach for improving child survival and development. We aimed to assess the knowledge and practices and to determine the factors affecting Infant and Young Child Feeding practices among mothers of children 0-23 months of Taluka Hospital Matli, Badin District, Sindh

Methods: A descriptive hospital-based cross-sectional study was conducted with the sample of 279 mothers visiting pediatric OPD of Taluka Hospital Matli, Badin District, Sindh-Pakistan from $1^{\text {st }}$ October to $31^{\text {st }}$ December 2016. The sample was collected by using non probability consecutive sampling technique and structured pretested questionnaire.

Results: $94 \%$ of women had the knowledge of when to start breastfeeding after delivery. There is a strong association between maternal education and 0-23 month's children receiving bottle feed and also a strong association between the information providers and bottle feeding practice.

Conclusion: We have found a good dependence of birth weight of the newborn with the monthly income of the household. LHWs and nurses were main sources of information provider about breastfeeding.

Keywords: IYCF, exclusive breastfeeding, complimentary feeding

\section{Introduction}

I Infant feeding is defined as breastfeeding for at least the first year of life and introduction of ironrich complementary foods around six months of life(1). The improved Infant and Young Child Feeding (IYCF) practices have become a key component of the child survival. IYCF is presented in the WHO/UNICEF Global Strategy of 2015 for Infant and
Young Child Feeding as a global public health recommendation; infants should be exclusively breastfed for the first six months of life to achieve optimal growth, development and health. Thereafter, to meet the evolving nutritional needs, infants should receive safe and nutritionally adequate complementary foods while breastfeeding continues for up to two years of age or beyond. In South Asia, only a quarter $(27 \%)$ of newborns start breastfeeding 
within 1 hour of birth (2). Estimates suggest that globally there are more than 150 million malnourished children under the age of 5 years. It is also well recognized that close to 35 percent of the estimated 9.2 million deaths among children under-five are associated with under nutrition and about a quarter $(26 \%)$ of the world's children under five live in South Asia, 38\% of them have stunted growth (2).

Childhood malnutrition is a public health priority to which one-third of child deaths are attributed. Long-term malnutrition manifests stunting, increases the risk of infections, reduced cognitive development and economic productivity (3). Global estimates for 2012 suggested that 51 million children under five were wasted, 162 million were stunted, and 99 million were underweight (3).

Directly or indirectly, the vicious cycle of malnutrition contributes to almost $35 \%$ of all under-5 deaths in Pakistan. Exclusive breastfeeding for up to 6 months can prevent up to $13 \%$ of the estimated under five deaths and appropriate complementary feeding can prevent almost $6 \%$ of under-five mortality (3). About two fifths of infants worldwide are exclusively breastfed for the first six months of life. Recent statistics of 2015, WHO showed that about $60 \%$ of all deaths, occurring among children aged less than five years in developing countries could be attributed to malnutrition(4).

In Pakistan $45 \%$ of children under-five are stunted or too short for their age. This indicates chronic malnutrition. Stunting is most common among children of less educated mothers (55\%) and those from the poorest households (62\%). Stunting is more common in rural areas (48\%) than urban areas (37\%). Wasting (too thin for height), which is a sign of acute malnutrition, is far less common (11\%). In addition, $30 \%$ of Pakistani children are underweight or too thin for their age (5). Globally malnutrition has been responsible, directly or indirectly, for about one third of the 8.1 million deaths annually among children $<5$ years. Over two-thirds of these deaths occur in the first year of life (6). Worldwide, suboptimal breastfeeding still accounts for deaths of 1.4 million children aged less than five years. It was estimated that if $90 \%$ of infants are covered with a package of intervention to protect, promote, and support the optimal IYCF practices, almost one-fifth of overall under-five mortality can be averted (7). Ultimately filling the gap of knowledge and improving the IYCF practices is the way of success. The results this study will not only elaborate the current status of IYCF practices but will also help to formulate the strategy for the future to gain better health outcomes.

\section{Methodology}

A descriptive cross sectional study was conducted at Taluka Hospital Matli District Badin from 1st October 2016 to 31st December 2016. The data was obtained from the survey of the mothers of the children aged 0-23 months visiting Taluka Hospital Matli. Data was collected through pretested structured questionnaire. Non probability consecutive sampling technique was used and around 11 children were selected each day till the desired number of sample size $n=279$ was obtained. The sample size was calculated by using formula $\mathrm{n}=\mathrm{Z} 2(\mathrm{p})(1-\mathrm{p}) / \mathrm{e}^{2}$ with the assumption that the prevalence of poor practices would be $50 \%$ among the mothers. Therefore, at $95 \% \mathrm{CI}$ and $5 \%$ margin of error the sample size was calculated $n=279$. Mothers of the children aged 0-23 months and willing to participate in the study were included, while mothers of the severely ill children and children with congenital abnormalities were excluded. The semi-structured questionnaire was designed in English and translated in local language Sindhi. It was important to design it in the local language to collect authentic data. Two senior lady health workers were recruited and trained by the principal researcher for data collection. Before enrolling participants, informed consent was taken from eligible mothers, to ensure their privacy. The questionnaire was reviewed by principal researchers on daily basis for reliability and to avoid errors before pre testing. For the purpose of data analysis, SPSS 21 was used. Frequencies and percentages were calculated for categorical variables and chi-square test was used to determine association respectively.

\section{Results}

The study comprises two parts, descriptive and inferential, the descriptive part contains sociodemographic characteristics and inferential part contains the chi-square test to explore the association of mother's knowledge and practices with demographic variables.

Socio-demographic and economic characteristics: $59.50 \%$ of mothers were illiterate and almost $26 \%$ had '3-year' formal school education. 14.3\% mothers had been exposed to secondary school level whereas 
higher levels of education were almost absent (except for just a single case $-0.4 \%)$. $81 \%$ of household had less than 10,000 rupees income and $19 \%$ had more than 10,000 rupees. $96 \%$ of the participants had only one child within the age range of 0-23 months, while only $4 \%$ had more than one child.

Infant and young child feeding practices: Eighty percent $(80 \%)$ of the newborn's birth weight was recorded at the time of birth and 20\% (a sizable proportion) is seen to be missed and quite big apparently. Children lying in the "Low Birth Weight" category are around $10 \%$, whereas the total of infant's weight till $3 \mathrm{~kg}$ at birth is $43 \%$. This shows that a majority of $57 \%$ was well above the minimal birth weight requirements. A very simple Ddistribution of sex among the 0-23 months' children of the visiting mothers was $54 \%$ male and $46 \%$ females. Almost $72 \%$ of the mothers started feeding within the first hour after birth, and a further increase up to four hours accounts for almost $93 \%$ of the population under study. $4.3 \%$ of the mothers delayed feeding till5-7 hours' after birth. (Table-1)

Table 1: Infant and young child feeding practices

\begin{tabular}{|l|l|l|l|}
\hline Variable & \multicolumn{1}{|c|}{ Category } & \multicolumn{1}{c|}{ Number } & \multicolumn{1}{c|}{$\%$} \\
\hline $\begin{array}{l}\text { Infant's } \\
\text { weight } \\
\text { recorded at } \\
\text { birth }\end{array}$ & Yes & 225 & 80.6 \\
\hline $\begin{array}{l}\text { Neonatal } \\
\text { birth } \\
\text { weight }\end{array}$ & $1-2 \mathrm{~kg}$ & 54 & 19.4 \\
& $>2 \mathrm{~kg}$ & 28 & \\
\hline$>3 \mathrm{~kg}$ & 92 & 10.0 \\
& Not weighted & 106 & 33.0 \\
Sex of & Male & 150 & 38.0 \\
child & Female & 129 & 19.0 \\
\hline Time taken & Immediately & 200 & 46.8 \\
after birth & within $1 / 2 \mathrm{hr}$ & 60 & 71.7 \\
to start BF. & $1-4 \mathrm{hr}$ & 12 & 21.5 \\
& $5-7 \mathrm{hr}$ & 6 & 4.3 \\
& Don't know & 1 & 2.2 \\
\end{tabular}

Most (98.6\%) of women fed their child on the basis of demand, day and night feeding schedule whereas $1.4 \%$ of the study population used "Time bound" feeding schedule. $63 \%$ of the participants did not give external milk to their child and $1 \%$ did once a week, whereas the aggregate of those using external milk daily once or more was $19.4 \%$ and $16.5 \%$ respectively. $38.7 \%$ mothers administrated local market milk products to their 0-23 month children and 61.3\% women preferred home-made foods alone and seldom preferred readymade food. (Table-2)

It was found that almost $90 \%$ of the women received valuable information regarding breast feeding practices from nurses, LHWs, or friends/relatives. $65 \%$ of the mothers got this information from the nurses, during and after their pregnancy. $18 \%$ of the women received information on Exclusive Breast Feeding in rural setup through LHWs and $16 \%$ were informed by their relatives. The other sources (like newspapers, TV, etc.) collectively accounted for less than $5 \%$.

Regarding the concepts of Exclusive Breast Feeding, even though a larger proportion of mothers had a clear concept (knowledge), the practice did not yield comparable results. Just $42 \%$ of the mothers Exclusively Breast Fed their children for 6 months, while $58 \%$ of the mothers, started complimentary foods before the completion of 6 months. (Table-3)

Table 2: Breast feeding and feeding practices

\begin{tabular}{|c|c|c|c|}
\hline Variable & Category & Number & $\%$ \\
\hline $\begin{array}{l}\text { Schedule of } \\
\text { feeding }\end{array}$ & $\begin{array}{l}\text { On Demand } \\
\text { Time bound }\end{array}$ & $\begin{array}{l}275 \\
4\end{array}$ & $\begin{array}{l}98.6 \\
1.4\end{array}$ \\
\hline $\begin{array}{l}\text { Use of any } \\
\text { infant } \\
\text { formula or } \\
\text { commercial } \\
\text { milk }\end{array}$ & $\begin{array}{l}\text { Never } \\
\text { Weekly once } \\
\text { Daily once } \\
\text { Daily >once }\end{array}$ & $\begin{array}{l}176 \\
3 \\
54 \\
46\end{array}$ & \begin{tabular}{l|l|}
63.1 & \\
1.1 \\
19.4 \\
16.5
\end{tabular} \\
\hline $\begin{array}{l}\text { Use of } \\
\text { readymade } \\
\text { food }\end{array}$ & $\begin{array}{l}\text { Yes } \\
\text { No }\end{array}$ & $\begin{array}{l}108 \\
171\end{array}$ & $\begin{array}{l}38.7 \\
61.3\end{array}$ \\
\hline
\end{tabular}

Table 3 : Knowledge regarding IYCF

\begin{tabular}{|l|l|l|l|}
\hline Variable & \multicolumn{1}{|c|}{ Category } & Number & $\%$ \\
\hline $\begin{array}{l}\text { BF messages in } \\
\text { Antenatal } \\
\text { visits }\end{array}$ & No & 249 & 89.2 \\
\hline $\begin{array}{l}\text { Age of child to } \\
\text { start solid food }\end{array}$ & 30 & 10.8 \\
\hline
\end{tabular}

About $92 \%$ of the women replied affirmative in response to the question, if they let their child take colostrum after birth. Just $6.5 \%$ of the respondents replied in negative94\% women knew it very well that the newborn child is to be fed with breast feeding in the first hour of birth. Almost 3\% were unaware of advantages of colostrum.

The cross-tabulation between maternal education and children receiving bottle feeding shows 
significant difference given in Table4. Among the uneducated, 33 out of 166 (19.9\%) were using a bottle,whereas the majority of mothers in this group $(80 \%)$ did not use bottle to feed their children. In comparison, among the "Educated" mothers (which includes 3-year school education as well); the proportion of children on bottle feed is found quite high i.e. $41.6 \%$ and only $58.4 \%$ of mothers did not use bottle feed. One of the probable reasons, as inferred from their interviews, could be their involvement in extra-domestic affairs and their confidence that they might better handle the hygiene matters connected to the bottle. The uneducated on the contrary followed the cultural values, where breast feeding has remained the only way for feeding the young ones in old rural setups, and did not allow new methods of feeding to infiltrate their practices.

Whatever the reason, the association seems strong enough. This is evident from the Fisher Exact tests as well. The p value of " 0.000 " is a highly significant. It might, therefore, be concluded from this cross-tabulation, that a strong association does exist between maternal education and 0-23 month old children receiving bottle feed, in our study. (Table-4).

Table 4: Maternal Education with Child receiving bottle feed

\begin{tabular}{|l|l|c|c|l|}
\hline Variable & Category & \multicolumn{2}{|c|}{$\begin{array}{c}\text { Child } \\
\text { receiving } \\
\text { Bottle feed }\end{array}$} & P value \\
\cline { 3 - 5 } & & Yes & No & \\
\hline Maternal & No Education & 33 & 133 & 0.000 \\
Education & $<3$ yrs of & 35 & 37 & \\
& education & 12 & 28 & \\
& Sec school ducation & 0 & 01 & \\
& Higher education & & & \\
\hline
\end{tabular}

Another very important cross-tabulation between "household income" and the "Birth weight" of the child shows some impact of the financial status with the outcome of the pregnancy in the form of the birth weight of the newborn, supposedly owing to better nutrition and care of the mother in relatively more affording members of the community. The low income group has shown a very high percentage $(11.5 \%)$ of "Low birth weight children". In comparison, there were only $3.8 \%$ of Low birth wt. children among those who earned more than 10,000/PKR per month. Similarly, children having a birth weight higher than $3 \mathrm{kgs}$ (healthier ones) were 49\% among richer ones, in comparison with only 35\% among the low income group mothers.

The study shows a p-value of 0.007 which is far safer than the required value. We can, therefore, conclude that in our study, we have found a good dependence of birth weight of the newborn with the monthly income of the household. (Table-5).

Table 5: Total monthly income of Household $X$ Neonatal birth weight

\begin{tabular}{|l|l|l|l|l|l|}
\hline Variable & \multicolumn{4}{|c|}{ Neonatal b weight } & P value \\
\cline { 1 - 4 } $\begin{array}{l}\text { Total } \\
\text { monthly } \\
\text { income }\end{array}$ & $\begin{array}{l}1-2 \\
\mathrm{~kg}\end{array}$ & $\begin{array}{l}2-3 \\
\mathrm{~kg}\end{array}$ & $\begin{array}{l}>3 \mathrm{k} \\
\mathrm{g}\end{array}$ & $\begin{array}{l}\text { Not } \\
\text { weighed }\end{array}$ & \\
\hline $\begin{array}{l}<10,000 \\
>10,000\end{array}$ & 26 & 70 & 80 & 50 & 0.007 \\
02 & 22 & 26 & 03 & \\
\hline
\end{tabular}

\section{Discussion}

Ninety percent of women had good information on initiation of breast feeding within the first hour after birth. This is inconsistent with study conducted in Nepal that showed that only $35 \%$ of the mothers had knowledge about breastfeeding initiation within one hour (8). Another study conducted at urban area of Meerut India the core indicator of IYCF revealed very low IYCF practices. In all only $15.0 \%$ mothers started breastfeeding within 1 hour of birth (9). In a study conducted on IYCF practices in rural area of Nagpur out of all 363 subjects only 213 were put on breast feeding within one hour of birth, with a significant difference between male and female child (10). In another study during the survey in Bankura district only $13.6 \%$ of the study children were put to the breast within one hour of birth (11).

More than $95 \%$ of the mothers knew well about exclusive breast feeding but did not translate justifiably into their practice, as $17.2 \%$ of the mothers gave pre lacteals on the first day of birth. In comparison, in Nepal, only $62 \%$ of the mothers knew the exact time for Exclusive Breast Feeding, but the practice was found up to $82 \%(8)$.

Not only that the score of Exclusive Breast Feeding in this study lies well above some of those conducted in compatible countries of the region, some other IYCF principles are also found firmly established, to the level of praise. For instance, $98.6 \%$ of mothers fed their children 'on-demand', day \& night. $92 \%$ of the mothers fed colostrum to their babies, with a clear concept that it was good for them. Mothers elsewhere have been found to have a perverted concept of 
Knowledge and Practices Regarding Infant and Young Child Feeding among Mothers' Children 0-23 Months of Matli, District Badin, Sindh

colostrum as "bad milk". 94\% of the mothers had received information (from nurses, LHWs and friends \& family members) on complimentary feeding but did not havethe real correct concept of IYCF principles. During discussions with mothers it came up that many believed that before beginning with the solid foods, it was safe enough to start with thin porridge made from maize meal. Further, the complimentary foods did not meet the minimum required standards of the recommended IYCF guidelines, in connection to food diversity, consumption of breast milk, milk products, frequency of feeds, etc. A study conducted in Ethiopia showed that only $10.75 \%$ children aged 623 months received appropriate complementary feeding (12). In Vietnam, $<20 \%$ of infants are exclusively breastfed in the first 6 months, and complementary foods are often introduced too early and tend to be of poor quality (13). Study conducted in Bangladesh showed that 3 out of 5 children are currently undernourished, despite improving food availability (14). A study conducted in Zhao County in Hebei Province in 2011 China found that infant feeding practices were poor, only $32.5 \%$ of children were given iron-rich or iron fortified food (15). In Meerut (India) 29.8\% started complementary feeding at 6 months (9). In India, 29\% children received bottle milk in comparison with $71 \%$ of those following strict IYCF principles in this regard, $37 \%$ were seen violating the IYCF recommended practices. In study of India $61.8 \%$ of mothers had a correct knowledge of avoiding bottle feeding, it reported that bottle feeding rate of $49 \%$ infant in study (16)The cross-tabulation of bottle milk use with that of economic status of the household has shown indifference of association.

\section{Conclusion}

Status of health indicators while assessing the "Knowledge" and "Practice" of IYCF among mothers of children of 0-23 months, among mothers who are visiting Taluka Hospital Matli, Badin District, Sindh (Pakistan) is found satisfactory. Most of mothers knew well about exclusive breast feeding but failed to translate justifiably into their practice. $17.2 \%$ of mothers did give pre lacteals on first day of birth.

\section{Competing Interests}

We declare that we have no competing interests.

\section{Acknowledgements}

We are grateful to Health Services Academy, Islamabad for giving ethical approval. Thanks to study participants, data collectors, Govt. of Sind and MS
Taluka Hospital Matli. Our study was sponsored by the USAID, Pakistan.

\section{References}

1. Wickes IG. A history of infant feeding. Primutve peoples: ancient works: renaissance writers. Dec: 1952. Sponsored. Protected by copyright. on August 15, 2020 at Pakistan:BMJ-PG http://adc.bmj.com/ Arch Dis Child: first published as $10.1136 /$ adc.28.138.151 on 1 April 1953. D

2. UNICEF. Programming Guide: infant and young child feeding. New York: Nutrition Section, Programmes, UNICEF; May 2011. p.1-165

3. Bentley A, Das S, Alcock G, More NS, Pantvaidya S, Osrin Ds. Malnutrition andinfant and young child feeding in informal settlements in Mumbai, India: findings from a census. 2015;2030:257-7.

4. Government of Pakistan. National Nutrition Survey 2011 Government of Pakistan. 2011.

5. National Institute of Population Studies (NIPS) [Pakistan] and ICF. 2018. Pakistan Demographic and Health. Survey 2017-18. Islamabad

6. Teji RK. Infant and Young Child Feeding (IYCF) Practices Among Mothers of Children Aged 6-23 Months in Two Agro-ecological

Zones of Rural Ethiopia. Int J Nutr Food Sci [Internet]. 2016;5(3):185.

7. Budimelli S, Chebrolu K. Infant and Young Child Feeding Practices in Guntur District - a Cross Sectional Study. J Evid Based Med Healthc [Internet]. 2015;2(56):8834-7.

8. Subedi N, Paudel S, Rana T, Ak P. Infant and Young Child Feeding Practices in Chepang Communities. 2012;10(2):141-6.

9. Singhal P, Garg SK, Chopra H, Jain S, Bajpai SK, Kumar A. Status of infant and young child feeding practices with special emphasis on breast feeding in an urban area of Meerut. J Dental and Medical Sciences. 2013 May;7:0.

10. Golawar SH, Parmar DR, Dahiphale BN. Infant and Young Child Feeding (IYCF) Practices in Rural Area of Nagpur. International Journal of Scientific Research. 2016 Mar 31;5(3).

11. Sinhababu A, Mukhopadhyay DK, Panja TK, Saren AB, Mandal NK, Biswas AB. Infant-and young child-feeding practices in Bankura district, West Bengal, India. Journal of health, population and nutrition. 2010 Jun 1:294-9.

12. Ergib M, Ashenafi Shumey, Semaw Ferede, Fisaha Haile. Magnitude and Factors Associated with Appropriate Complementary Feeding among Mothers Having Children 6-23 Months-of-Age in Northern Ethiopia; A Community-Based Cross-Sectional Study. Journal of Food and Nutrition Sciences. Vol. 2, No. 2, 2014, pp. 36-42. doi: 10.11648/j.jfns.20140202.13. 
13. Nguyen PH, Kim SS, Nguyen TT, Tran LM, Hajeebhoy N, Frongillo EA, et al. (2016) Supply- and Demand-Side Factors Influencing Utilization of Infant and Young Child Feeding Counselling Services in Viet Nam. PLoS ONE 11(3): e0151358. doi:10.1371/ journal.pone.0151358.

14. Mashreky SR, Rahman F, Rahman A, Talab A, Rahman $Z$. Role of mass media in increasing knowledge and practices of mothers on IYCF: Findings from a community trial in rural Bangladesh. 2015;5(1):18-24.
15. Wu Q, Scherpbier RW, Velthoven MH Van, Chen L, Wang W, Li Y, et al. Poor infant and young child feeding practices and sources of caregivers ' feeding knowledge in rural Hebei Province, China: fi ndings from a cross-sectional survey. 2014;1-9.

16. Ahmad SR, Thaher MA, Addepalli C. Knowledge and Attitudes of Anganwadi Workers about Breast Feeding in the Field Practice Area of Tertiary Care Hospital, Hyderabad. Natl J Community Med. 2016;7(5):413-6 